\title{
Improved Photovoltaic Performance of a Side- Chain D-A Polymer in Polymer Solar Cells by Shortening the Phenyl Spacer between the D and A Units
}

\author{
Wenyan Su, Qunping Fan, Manjun Xiao, Jianhua Chen, Pei Zhou, Bin Liu, \\ Hua Tan," Yu Liu, Renqiang Yang, Weiguo Zhu*
}

To study the influence of the spacer between the donor (D) and acceptor (A) units in a side chain on the photophysical and photovoltaic performance, a novel side-chain D-A conjugated copolymer of PDPAT-BDT-BT is made, which contains binary donor units of $\mathrm{N}, \mathrm{N}$-diphenylthiophen-2-amine (DPAT) and benzo[1,2-b:4,5- $\left.\mathrm{b}^{\prime}\right]$ dithiophene (BDT) in the main chain and an appending benzothiadiazole (BT) acceptor unit in the side chain. Compared with its counterpart of PDPAT-BDT-BT, which has an additional phenyl spacer between the DPAT and BT units, this PDPAT-BDT-BT exhibits a smaller optical bandgap, a broader absorption range, and a lower highest occupied molecular orbital (HOMO) energy level $(-5.42 \mathrm{eV})$, as well as improved photovoltaic properties in bulk heterojunction polymer solar cells containing [6,6]-phenyl$\mathrm{C}_{71}$-butyric acid methyl ester as an electron acceptor. A maximum power conversion efficiency of $3.27 \%$ with an open circuit voltage of $0.87 \mathrm{~V}$ and a fill factor of $49.8 \%$ are obtained in the cells. This work indicates that the photophysical and photovoltaic performance of the side-chain $\mathrm{D}-\mathrm{A}$ polymers in polymer solar cells can be significantly improved by shortening the phenyl spacer between the $\mathrm{D}$ and $\mathrm{A}$ units.

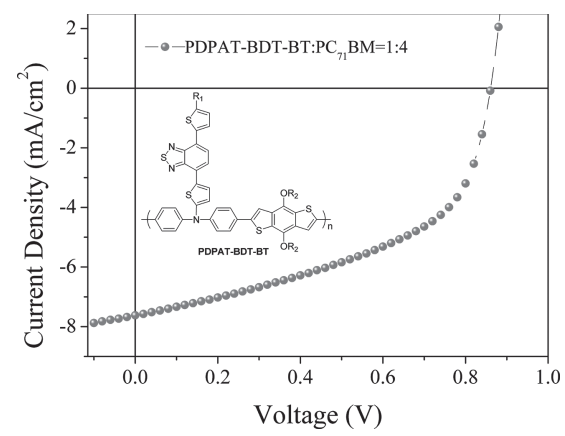

\section{Introduction}

Driven by the urgent need for a renewable energy supply, polymer photovoltaic technologies have been developed

W. Su, ${ }^{[+]}$O. Fan, ${ }^{[+]}$M. Xiao, J. Chen, P. Zhou, B. Liu, Dr. H. Tan, Y. Liu, Prof. W. Zhu

Key Lab of Environment-Friendly Chemistry and Application in Ministry of Education, College of Chemistry, Xiangtan

University, Xiangtan 411105 , China

E-mail: tanhua815@126.com; zhuwg18@126.com

Prof. R. Yang

Qingdao Institute of Bioenergy and Bioprocess Technology,

Chinese Academy of Sciences, Qingdao 266101, China

E-mail: yangrq@qibebt.ac.cn

${ }^{[+]}$These authors contributed equally to this work extensively in recent years. Bulk heterojunction (BHJ) polymer solar cells (PSCs) have specially attracted attention because of their potential for low cost and light weight, as well as their applications in flexible and largearea devices. ${ }^{[1]}$ The recorded power conversion efficiency (PCE) for reported PSCs has continually increased to the current value, which is higher than $10 \%{ }^{[2]}$ Most photovoltaic materials have been based on narrow-bandgap (NBG) polymers with a donor-acceptor (D-A) framework. ${ }^{[3]}$ The investigation has indicated that ideal polymers to be used as photovoltaic donor materials generally have a broad absorption with a high absorption coefficient in the visible region, high hole mobility, and suitable energy level matching with the fullerene acceptor, as well as a great discontinuous interpenetrating network for charge transport. ${ }^{[4]}$ 
To enlarge the absorption areas and increase the hole mobility, side-chain D-A conjugated copolymers were constructed using electron-rich donor moieties in the main chain and pending electron-deficient acceptor units onto donor units in the side chain. As an additional intramolecular charge transfer (ICT) exists from the D to the A units in the side chains, this class of polymers exhibits broad absorption and high hole mobility. ${ }^{[5]}$ Nevertheless, most of these side-chain D-A conjugated copolymers have not presented a comparable device performance to their main-chain D-A counterparts. Compared with their corresponding main-chain $\mathrm{D}-\mathrm{A}$ copolymers, the side-chain ones mainly possess three advantages. Firstly, the highest occupied molecular orbit (HOMO) energy levels can be maintained in a deeper position. Secondly, a 2D-like structural feature renders this class of copolymers with better solubility. Finally, there exists an ICT behavior between the $\mathrm{D}$ and $\mathrm{A}$ units in the side-chain, which can fine tune the bandgap $\left(E_{\mathrm{g}}\right)$ of the resultant copolymers, as well as promote an isotropic charge transport along the polymeric main chain. ${ }^{[6]}$ In order to study the influence of molecular structures of the side-chain D-A copolymers, in our earlier research, we developed a few of side-chain D-A conjugated copolymers containing benzo[1,2-b:4,5-b']dithiophene (BDT) unit in the main chain. The maximum PCE of $4.89 \%$, an open-circuit voltage $\left(V_{\mathrm{oc}}\right)$ of $0.84 \mathrm{~V}$, a shortcircuit current $\left(J_{\mathrm{sc}}\right)$ of $10.04 \mathrm{~mA} \mathrm{~cm}^{-2}$, and a fill factor $(F F)$ of $56.0 \%$ were obtained in PBDT-TDPP-S-based BHJ PSCs. ${ }^{[6]}$

As is well known, benzothiadiazole (BT) is a common acceptor unit with strong electron-withdrawing property owing to its strong light absorption, photochemical stability, and large-scale synthesis. ${ }^{[7]}$ It is often employed to couple with a variety of electron-rich groups to form NBG polymers and small molecules in BHJ solar cells. ${ }^{[8]}$ The above-mentioned BDT units have also been flourishing as electron-donor units in last few years, which can endow their D-A molecules with good thermal stabilities, low HOMO level, and the lowest unoccupied molecular orbit (LUMO) energy levels, as well as high hole mobility and greatly improved photovoltaic performance. ${ }^{[9]}$ Besides the above BT and BDT units, the triphenylamine (TPA) unit is one of the most popular organic optoelectronic units due to its good electron-donating and hole-transporting abilities, and it has been widely used as donor unit to construct D-A-type photovoltaic materials. ${ }^{[10]}$ Considering the above merits, we recently reported a side-chain D-A-type copolymer of PTPAT-BDT-BT, in which the main chain consists of TPA and BDT units, and the BT unit is attached into the TPA unit by a thienyl spacer to form the side chain. ${ }^{[6 c]}$ The introduction of the pendent BT unit endows this PTPAT-BDT-BT polymer with an improved photovoltaic property.

To further study the influence of the phenyl spacer between the DPA and BT units in the side chain on the
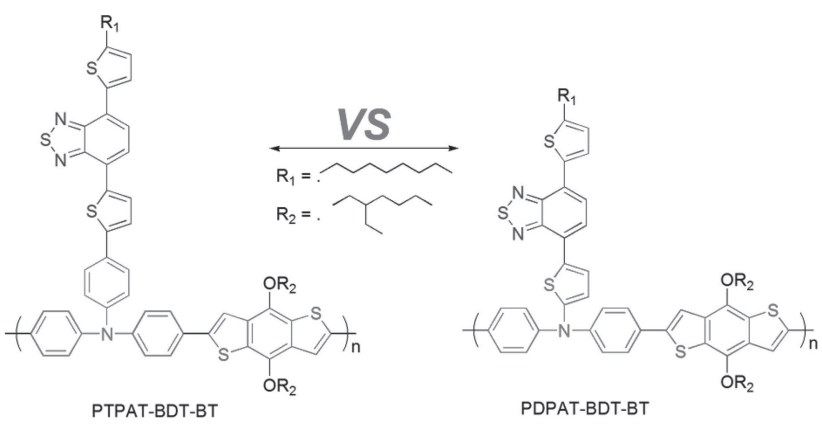

Figure 1. Molecular structure of the PTPAT-BDT-BT and PDPAT-BDT-BT.

photophysical and photovoltaic performances, in this paper, we report our continuous effort to construct another side-main D-A conjugated copolymer by shortening the phenyl spacer between the $\mathrm{D}$ and $\mathrm{A}$ unit. The molecular structures of the designed side-main D-A conjugated copolymer of PDPAT-BDT-BT and its counterpart of PTPAT-BDT-BT are shown in Figure 1. Compared with the previous PTPAT-BDT-BT, this novel PDPAT-BDT$\mathrm{BT}$ copolymer is removed from a phenyl spacer between the DPA and BT units. We found that the PDPAT-BDT-BT copolymer presented a lower optical bandgap (1.82 eV), a broader absorption range (300-680 nm), and a lower HOMO energy level $(-5.42 \mathrm{eV})$ than the PTPAT-BDTBT copolymer, as well as an enhanced hole mobility of $1.06 \times 10^{-4} \mathrm{~cm}^{2} \mathrm{~V}^{-1} \mathrm{~s}^{-1}$; these are suggested to be available for improving its photovoltaic properties. As expected, using PDPAT-BDT-BT instead of PTPAT-BDT-BT as electron donor and $\mathrm{PC}_{71} \mathrm{BM}$ as electron acceptor, the PSCs exhibited ameliorative photovoltaic properties except the short-circuit current density. The maximum PCE of $3.27 \%$ with a $V_{\text {oc }}$ of $0.87 \mathrm{~V}$ and a $F F$ of $49.8 \%$ was obtained in the PDPAT-BDT-BT-based devices. Therefore, shortening the phenyl spacer between the D and A units is an efficient approach to improve the photophysical and photovoltaic performance of these side-chain D-A copolymers.

\section{Results and Discussion}

\subsection{Synthesis and Characterization}

The syntheses of monomers and the PDPAT-BDT-BT copolymer are outlined in Scheme 1. 4-(5-(2-Ethylhexyl) thiophen-2-yl)-7-(thiophen-2-yl)benzo[c][1,2,5]thiadiazole (3) was obtained by the palladium-catalyzed Stille coupling reaction with a high yield. 4-(5-Lodothiophen-2-yl)-7-(5(2-ethylhexyl)thiophen-2-yl)benzo[c][1,2,5]thiadiazole (4) was easily prepared by halogenation under catalysis of a few drops of acetic acid at $0^{\circ} \mathrm{C}$. $\mathbf{M} \mathbf{1}$ was prepared by an Ullmann coupling reaction in a moderate yield. All the intermediates mentioned above were characterized by ${ }^{1} \mathrm{H} N M R$, 
<smiles>[R]c1ccc(-c2ccc(Br)c3nsnc23)s1</smiles>

4<smiles>OC(O)(O)c1ccc(Nc2ccc(Br)cc2)cc1</smiles><smiles>[R]c1ccc(-c2ccc(-c3ccc(N(c4ccc(Br)cc4)c4ccc(Br)cc4)s3)c3nsnc23)s1</smiles>

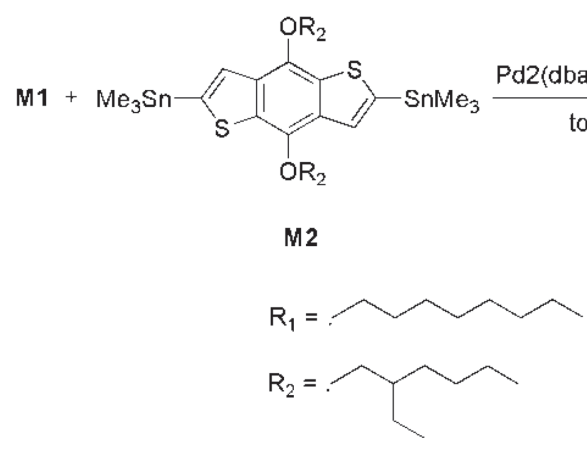<smiles>[R2]Oc1c2cc(C(C)(C)C)sc2c(O[R2])c2cc(-c3ccc(N(c4ccc(C(C)(C)C)cc4)c4ccc(-c5ccc(-c6ccc([R])s6)c6nsnc56)s4)cc3)sc12</smiles>

Scheme 1. Synthesis of the PDPAT-BDT-BT.

some by ${ }^{13} \mathrm{C}$ NMR, and matrix-assisted laser desorption/ ionization time-of-flight mass spectrometry (MALDITOF MS) (see Supporting Information). The copolymer of PDPAT-BDT-BT was obtained by a Stille coupling reaction according to methods described in the literature, ${ }^{[11]}$ and was characterized by ${ }^{1} \mathrm{H}$ NMR. Its number-average molecular weight $\left(\bar{M}_{n}\right)$, weight-average molecular weight $\left(\bar{M}_{\mathrm{w}}\right)$, and polydispersity index (PDI) were determined by GPC. The resulting data are shown in Table 1. It is shown that PDPAT-BDT-BT has a $\bar{M}_{\mathrm{n}}$ of $2.54 \times 10^{4} \mathrm{~g} \mathrm{~mol}^{-1}$ with a PDI of 3.08, which is 2.5 times higher than that of the previous PTPAT-BDT-BT copolymer. Furthermore, good solubility in conventional organic solvents were also observed at room temperature (RT), such as chloroform $\left(\mathrm{CHCl}_{3}\right)$, tetrahydrofuran (THF), chlorobenzene (CB), and dichlorobenzene (DCB), which is adequate for applications in PSCs and other optoelectronic devices.

\subsection{Thermal Properties}

The thermal properties of the PDPAT-BDT-BT were determined by differential scanning calorimetry (DSC) under a nitrogen atmosphere at a heating rate of $10{ }^{\circ} \mathrm{C} \mathrm{min}-1$. The DSC curve is shown in Figure S1 (see Supporting Information). No apparent thermal transition up to $240{ }^{\circ} \mathrm{C}$ is exhibited, indicating that this copolymer possesses an

Table 1. Molecular weight and thermal properties of the PDPAT-BDT-BT and PTPAT-BDT-BT.

\begin{tabular}{lccccc}
\hline Copolymer & $\begin{array}{c}\overline{\boldsymbol{M}}_{\mathrm{n}}{ }^{\mathrm{a})} \\
{\left[\mathrm{g} \mathrm{mol}^{-1}\right]}\end{array}$ & $\begin{array}{c}\overline{\boldsymbol{M}}_{\mathrm{w}}{ }^{\mathrm{a}} \text { ) } \\
{\left[\mathrm{g} \mathrm{mol}^{-1}\right]}\end{array}$ & PDI $^{\mathrm{a})}$ & $\begin{array}{c}T_{\mathrm{d}}{ }^{\mathrm{b})} \\
{\left[{ }^{\circ} \mathbf{C}\right]}\end{array}$ & Ref. \\
\hline PDPAT-BDT-BT & $2.54 \times 10^{4}$ & $10.90 \times 10^{4}$ & 3.08 & 332 & This work \\
PTPAT-BDT-BT & $1.01 \times 10^{4}$ & $1.27 \times 10^{4}$ & 1.25 & 360 & {$[6 \mathrm{c}]$}
\end{tabular}

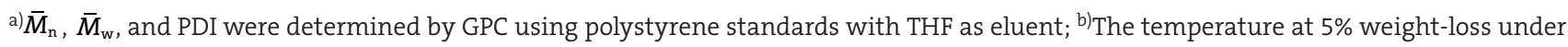
nitrogen. 


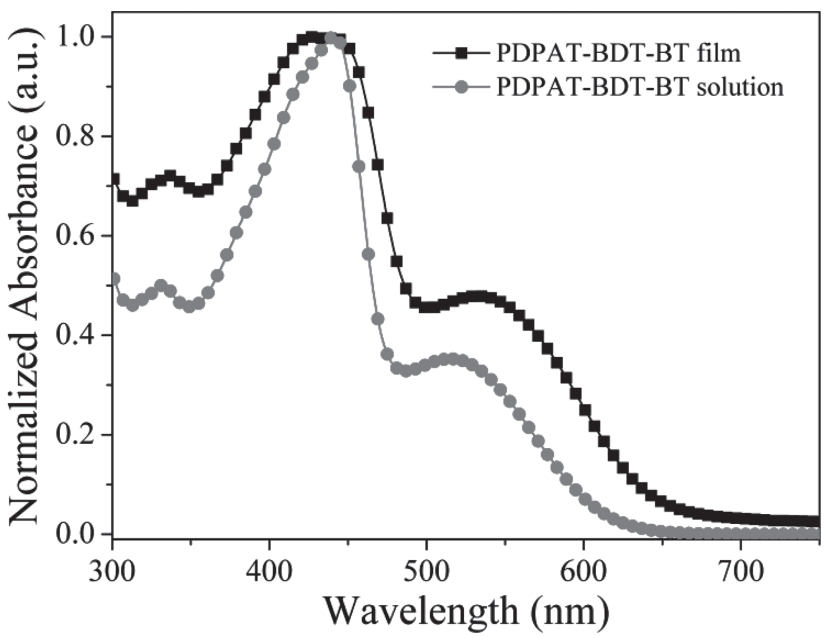

Figure 2. Normalized UV-vis absorption spectra of the PDPATBDT-BT in dilute $\mathrm{CHCl}_{3}$ and its neat film at RT.

amorphous nature below $240{ }^{\circ} \mathrm{C}$. The thermal stability of the PDPAT-BDT-BT was further investigated using thermogravimetric analysis (TGA) under a nitrogen atmosphere at a heating rate of $20^{\circ} \mathrm{C} \mathrm{min}-1$, as shown in Table 1 and Figure S2 (see Supporting Information). A decomposition temperature of $332{ }^{\circ} \mathrm{C}$ at $5 \%$ weight-loss is observed, which implies this copolymer has a high thermal stability.

\subsection{Optical Properties}

The normalized UV-vis absorption spectra of PDPAT-BDTBT in dilute $\mathrm{CHCl}_{3}$ solution and in thin film are shown in Figure 2, and the maximum absorption wavelengths are listed in Table 2. In $\mathrm{CHCl}_{3}$ solution, two obvious absorption peaks are observed. The first one at ca. $440 \mathrm{~nm}$ corresponds to the $\pi-\pi^{*}$ transition of the polymeric backbone in the short-wavelength region. ${ }^{[12]}$ The second one at ca. $515 \mathrm{~nm}$ in the long-wavelength region is attributed to the ICT interaction between the D and A units in the sidechain. ${ }^{[13]}$ Compared with the absorption spectrum in $\mathrm{CHCl}_{3}$ solution, the one in solid film has a $25 \mathrm{~nm}$ red-shift profile with a broader absorption band (300-680 nm). This red-shifted phenomenon is related to the enhanced interchain interaction in the solid films, which results in an increased extent of $\pi-\pi$ stacking of the backbones. ${ }^{[14]}$ The extended absorption edge in the long-wavelength region to some extent can be attributed to the more aggregated configuration formed in the solid state. Compared with the previous PTPAT-BDT-BT copolymer with an additional phenyl spacer, this PDPAT-BDT-BT copolymer exhibits a significantly red-shifted absorption profile by $20 \mathrm{~nm}$, both in $\mathrm{CHCl}_{3}$ solution and in the solid. Here, withdrawing a phenyl spacer between the $\mathrm{D}$ and $\mathrm{A}$ units in the side-chain is useful for its copolymer to shift the absorption spectrum to a longer wavelength. As a result, the optical bandgap $\left(E_{\mathrm{g}}{ }^{\text {opt }}\right)$ of PDPAT-BDT-BT is shifted to $1.82 \mathrm{eV}$ calculated from the onset of absorption spectra in solid film.

\subsection{Electrochemical Properties}

Cyclic voltammetry (CV) was employed to investigate the redox behavior of polymer and estimate the HOMO and LUMO energy levels ( $E_{\text {HOMO }}$ and $\left.E_{\text {LUMO }}\right)$. Both potentials were calibrated against an internal standard of the ferrocene/ferrocenium $\left(\mathrm{Fc} / \mathrm{Fc}^{+}\right)$couple. The recorded $\mathrm{CV}$ curve is shown in Figure 3 and the corresponding data are summarized in Table 2.

The HOMO and LUMO energy levels of the polymer, as well as the electrochemical bandgap $\left(E_{\mathrm{g}}{ }^{\mathrm{ec}}\right)$ were calculated according to the empirical formulas: $E_{\mathrm{HOMO}}=-\left(E_{\mathrm{ox}}+\right.$ 4.44) $\mathrm{eV}, E_{\text {LUMO }}=-\left(E_{\text {red }}+4.44\right) \mathrm{eV}$, and $E_{\mathrm{g}}{ }^{\mathrm{ec}}=-\left(E_{\text {ox }}-E_{\text {red }}\right) \mathrm{eV}$, where $E_{\text {ox }}$ is the onset oxidation potential and $E_{\text {red }}$ is the onset reduction potential for the polymer. As a result, the HOMO and LUMO energy levels of the PDPAT-BDT-BT are -5.42 and $-3.60 \mathrm{eV}$. Here, the PDPAT-BDT-BT copolymer exhibits a decreasing $E_{\text {HOMO }}$ value and an increasing $E_{\text {LUMO }}$ value compared with the PTPAT-BDT-BT copolymer. The low HOMO energy level is beneficial to maintain a relatively high $V_{\text {oc }}{ }^{[15]}$ In addition, its $E_{\mathrm{g}}{ }^{\text {ec }}$ is larger than its $E_{\mathrm{g}}{ }^{\text {opt: }}$ the discrepancy might be induced by the presence of an energy barrier at the interface between the polymer film and the electrode surface. ${ }^{[16]}$

\subsection{Theoretical Calculations}

In order to better understand the influence of the phenyl spacer between the D and A units in the side chain, the optimal geometries and electronic structures of PDPATBDT-BT and PTPAT-BDT-BT were simulated by density functional theory (DFT) calculations with Gaussian at the B3LYP/6-31G* level. As shown in Figure S3a (see Supporting Information), it can be found that PDPAT-BDT-BT

Table 2. Optical and electrochemical properties of the polymers.

\begin{tabular}{|c|c|c|c|c|c|c|c|}
\hline Copolymer & $\begin{array}{c}\lambda_{\max } \text { (solution) } \\
{[\mathrm{nm}]}\end{array}$ & $\begin{array}{c}\lambda_{\max }(\text { film }) \\
{[\mathrm{nm}]}\end{array}$ & $\begin{array}{c}E_{\text {g(opt) }}^{\text {a) }} \\
\text { [V] }\end{array}$ & $\begin{array}{c}E_{\text {HOMO }}{ }^{\mathrm{b})} \\
{[\mathrm{eV}]}\end{array}$ & $\begin{array}{c}E_{\text {LUMO }}{ }^{c)} \\
{[\mathrm{eV}]}\end{array}$ & $\begin{array}{c}E_{\mathrm{g}(\mathrm{ec})}^{\mathrm{d})} \\
{[\mathrm{eV}]}\end{array}$ & Ref. \\
\hline PDPAT-BDT-BT & 440,515 & 435,540 & 1.82 & -5.42 & -3.60 & 1.82 & This work \\
\hline PTPAT-BDT-BT & 433,493 & 518 & 1.93 & -5.38 & -3.57 & 1.81 & {$[6 c]$} \\
\hline
\end{tabular}

a) Optical energy gap determined from the onset position of the absorption band; b) HOMO position (vs. SCE) determined from onset of oxidation; c)LUMO position (vs. SCE) determined from onset of reduction; ${ }^{\mathrm{d})}$ Electrochemical energy gap. 
has a better planarity than PTPAT-BDT-BT. A twisting conformation for the side-chain of PTPAT-BDT-BT appears. As shown in Figure S3b (Supporting Information), the HOMO of PDPAT-BDT-BT demonstrates a more-extended electron delocalization compared with that of PTPAT-BDT-BT on the $\mathrm{D}$ and $\mathrm{A}$ repeat units. The good planarity of PDPAT-BDT-BT is suggested to be available to increase the $\pi-\pi$ stacking, improve the charge-transfer ability, and lower the HOMO energy level. ${ }^{[17]}$ The better electron delocalization property of PDPAT-BDT-BT is available to increase the orbital overlap between HOMO and LUMO, and enhance the absorption coefficient. ${ }^{[18]}$ Therefore, the simulated results by DFT calculations indicate that PDPTA-BDT-BT should display better photovoltaic properties in PSCs.

\subsection{Hole Mobility}

In order to get some ideas about the influence of molecular structures on their charge-transporting properties, the hole mobility of PDPAT-BDT-BT was measured by the space charge limited current (SCLC) method. ${ }^{[19]}$ Figure S4 (see Supporting Information) shows the $J$ vs $V$ characteristics of PDPAT-BDT-BT obtained in the dark for its hole-only device with the configuration ITO/PEDOT:PSS (40 nm)/active layer $(130 \mathrm{~nm}) / \mathrm{Ca}(10 \mathrm{~nm}) / \mathrm{Al}(100 \mathrm{~nm})$. The hole mobility of $1.06 \times 10^{-4} \mathrm{~cm}^{2} \mathrm{~V}^{-1} \mathrm{~s}^{-1}$ was obtained in the PDPAT-BDT-BTbased hole-only device. Compared with previous PTPAT-BDT$\mathrm{BT},{ }^{[6 c]}$ this PDPAT-BDT-BT copolymer exhibited dramatically enhanced hole mobility. The improved hole mobility is coincident with the good planarity of PDPAT-BDT-BT simulated by DFT calculations. Such a high hole mobility for PDPATBDT-BT is responsible for the high $F F$ level in the devices.

\subsection{Photovoltaic Properties}

To demonstrate the photovoltaic properties of PDPAT-BDTBT, its copolymer solar cells were made under thermal annealing temperature of $110{ }^{\circ} \mathrm{C}$ using $\mathrm{PC}_{61} \mathrm{BM}$ or $\mathrm{PC}_{71} \mathrm{BM}$ as electron acceptor with a configuration of indium tin oxide (ITO)/poly(3,4-ethylenedioxythiophene):polystyrene sulfonate (PEDOT:PSS) (30 nm)/active layer $(80 \mathrm{~nm}) / \mathrm{Ca}$ $(0.7 \mathrm{~nm}) / \mathrm{Al}(100 \mathrm{~nm})$, in which the active layer consist of PDPAT-BDT-BT and $\mathrm{PC}_{61} \mathrm{BM}$ (or $\mathrm{PC}_{71} \mathrm{BM}$ ). The ratios between PDPAT-BDT-BT and $\mathrm{PC}_{61} \mathrm{BM}$ were adjusted from 1:2 to 1:4.5 (by weight) in order to optimize the device performance. The current-density-voltage $(J-V)$ characteristics of the PDPAT-BDT-BT/PC ${ }_{61}$ BM-based devices are shown in Figure S5 (see Supporting Information) at different D/A ratios and their corresponding photovoltaic data are summarized in Table S1 (see Supporting Information). The optimized ratio between PDPAT-BDT-BT and $\mathrm{PC}_{61} \mathrm{BM}$ of $1: 4$ was obtained. Under this optimized ratio, the influence of 1,8-diiodooctance (DIO) additive concentrations and the active layer thickness on the photovoltaic properties was

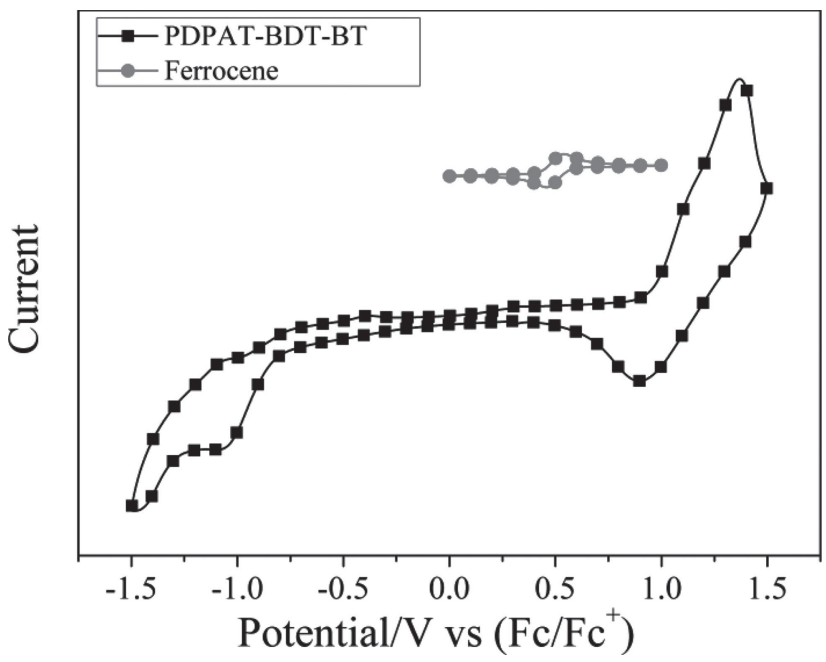

Figure 3. Cyclic voltammetry curve of the PDPAT-BDT-BT.

studied. The resulting $J-V$ characteristics of the PDPATBDT-BT/PCBM-based devices at different DIO concentrations and active layer thicknesses are shown in Figure S6 (see Supporting Information) and Figure S7 (see Supporting Information), respectively. Their corresponding photovoltaic properties are listed in Table S2 (see Supporting Information) and Table S3 (see Supporting Information), respectively. We find that the device exhibited best photovoltaic properties at the optimized conditions such as $1 \%$ of DIO concentration and thickness of $85 \mathrm{~nm}$ since adding a certain amount of DIO can facilitate the formation of a nanoscale phase of copolymers $/ \mathrm{PC}_{61} \mathrm{BM}$ blends. ${ }^{[20]}$ At the optimized ratio of the DIO concentration and thickness, two typical devices were then made using $\mathrm{PC}_{61} \mathrm{BM}$ or $\mathrm{PC}_{71} \mathrm{BM}$ as acceptor to study the effect of the acceptor on the photovoltaic properties.

Figure 4 shows the resulting $J-V$ characteristics under $1000 \mathrm{~W} \mathrm{~m}^{-2}$ air mass 1.5 global (AM $1.5 \mathrm{G}$ ) illumination. Device parameters such as $J_{\mathrm{SC}}, V_{\mathrm{oc}}, F F$, and PCE are deduced from the $J-V$ characteristics and summarized in Table 3.

It is clear that the PDPAT-BDT-BT/PC ${ }_{71} \mathrm{BM}$-based devices exhibited better photovoltaic properties as compared

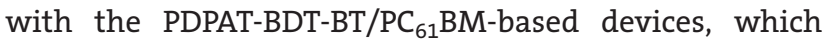
can be attributed to the stronger absorption of $\mathrm{PC}_{71} \mathrm{BM}$ than $\mathrm{PC}_{61} \mathrm{BM}$ in the visible region from 440 to $530 \mathrm{~nm} .^{\text {[6a] }}$ The maximal PCE of $3.27 \%$ with a $V_{\text {oc }}$ of $0.87 \mathrm{~V}$, a $J_{\text {sc }}$ of $7.61 \mathrm{~mA} \mathrm{~cm}^{-2}$, and a $F F$ of $49.8 \%$ was achieved for the PDPAT-BDT-BT/PC ${ }_{71}$ BM-based devices. Compared with the PTPAT-BDT-BT/PC ${ }_{71}$ BM-based devices reported before, ${ }^{[6 \mathrm{c}]}$ the devices here exhibit better photovoltaic properties with increasing PCE and FF values.

To confirm why the PDPAT-BDT-BT/PC ${ }_{71}$ BM-based devices exhibited higher PCE than PTPAT-BDT-BT/PC ${ }_{61} \mathrm{BM}-$ based devices, the external quantum efficiencies (EQES) of the PDPAT-BDT-BT/PCBM blend films at the optimized

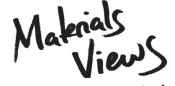

www.MaterialsViews.com 


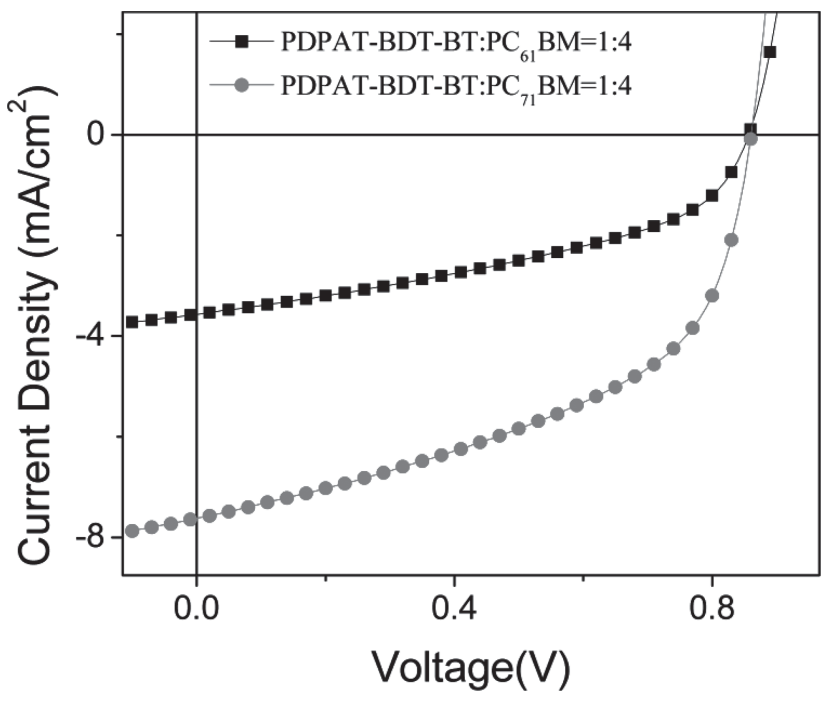

Figure 4. $J-V$ characteristics of the PDPAT-BDT-BT-based PSCS under simulated AM $1.5 \mathrm{G}$ illumination $\left(1000 \mathrm{~W} \mathrm{~m}^{-2}\right)$.

ratio of 1:4 illuminated by monochromatic light were determined and shown in Figure 5.

A high $E Q E$ over $40 \%$ is observed in a very broad range from 350 to $580 \mathrm{~nm}$, and the highest $E Q E$ of $58 \%$ locates at $420 \mathrm{~nm}$ for the PDPAT-BDT-BT/PC ${ }_{71} \mathrm{BM}$ blend film. However, a high $E Q E$ over $40 \%$ is limited in a very narrow range from 380 to $428 \mathrm{~nm}$, and the highest EOE of $44 \%$ locates at $400 \mathrm{~nm}$ for the PDPAT-BDT-BT/PC ${ }_{61} \mathrm{BM}$ blend film. Therefore, the PDPAT-BDT-BT/PC ${ }_{71} B M$ blend film shows a more-efficient photoresponse than the PDPAT$\mathrm{BDT}-\mathrm{BT} / \mathrm{PC}_{61} \mathrm{BM}$ blend film in the broad range from 310 to $730 \mathrm{~nm}$. Furthermore, the integral of the $E O E$ is in accordance with $J_{\mathrm{sc}}$ measured from the devices.

The surface morphology of the active layers was studied using atomic force microscopy (AFM) under tapping mode in order to further understand why the device exhibited better photovoltaic properties at the annealing temperature of $110^{\circ} \mathrm{C}$. Figure S8 (see Supporting Information) shows typical AFM topography of the PDPAT-BDT$\mathrm{BT} / \mathrm{PC}_{71} \mathrm{BM}$ blend film in annealed and unannealed conditions. The surface roughnesses are observed to be $2.15 \mathrm{~nm}$ (a) in the unannealed condition and $1.50 \mathrm{~nm}$ (b) in the annealed condition. This implies that the PDPAT-BDT$\mathrm{BT} / \mathrm{PC}_{71} \mathrm{BM}$ blend film has a better surface morphology without large phase separation under the annealed condition than it does in the unannealed condition. Therefore,

Table 3. Photovoltaic properties of the PDPAT-BDT-BT-based PSCs under simulated AM 1.5 G illumination $\left(1000 \mathrm{~W} \mathrm{~m}^{-2}\right)$.

\begin{tabular}{lcccc}
\hline Acceptor & $\begin{array}{c}J_{\text {sc }} \\
{\left[\mathrm{mA} \mathrm{cm}^{-2}\right]}\end{array}$ & $\begin{array}{c}\boldsymbol{V}_{\text {oc }} \\
{[\mathbf{V}]}\end{array}$ & $\begin{array}{c}\text { FF } \\
{[\%]}\end{array}$ & $\begin{array}{c}\text { PCE }_{\max } \\
{[\%]}\end{array}$ \\
\hline $\mathrm{PC}_{61} \mathrm{BM}$ & 3.29 & 0.85 & 43.1 & 1.21 \\
$\mathrm{PC}_{71} \mathrm{BM}$ & 7.61 & 0.87 & 49.8 & 3.27
\end{tabular}

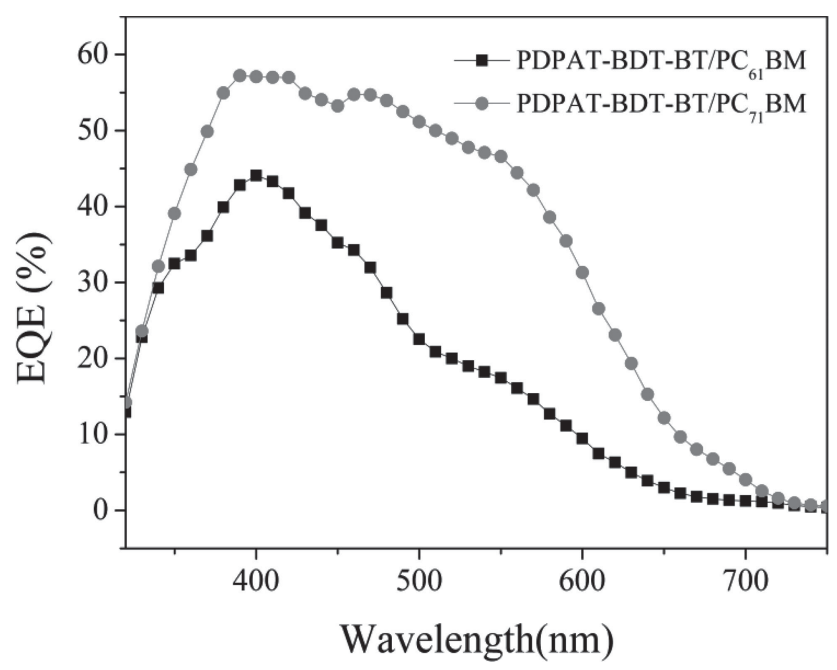

Figure 5. EQE curves of the PDPAT-BDT-BT/PCBM-based devices.

the surface roughness of the blend film can be tuned to be much smoother by prethermal annealing. The smooth morphology of the active layer is available for improving the device performance.

\section{Conclusion}

We obtained a novel NBG side-chain D-A conjugated copolymer of PDPAT-BDT-BT, which contains a main chain of the DPAT-alt-BDT donor and a side chain of the BT acceptor. A significant influence of the phenyl spacer between the $\mathrm{D}$ and $\mathrm{A}$ units in the side chain on the photophysical and photovoltaic performances was observed. An improved PCE of $3.27 \%$ with a $V_{\text {oc }}$ of $0.87 \mathrm{~V}$ and a $F F$ of $49.8 \%$ were obtained in the PDPAT-BDT-BT-based PSCs under the illu-

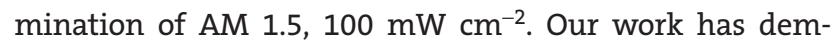
onstrated that shortening the phenyl spacer between the $\mathrm{D}$ and $\mathrm{A}$ units in the side chain is an efficient way for its copolymer to have improved photophysical and photovoltaic performance in polymer solar cells.

\section{Experimental Section}

\subsection{Instruments and Characterization}

NMR spectra were recorded on a Bruker DRX 400 spectrometer using tetramethylsilane as a reference in deuterated $\mathrm{CHCl}_{3}$ solution at $298 \mathrm{~K}$. MALDI-TOF mass spectrometry measurements were performed on a Bruker Bifiex III MALDI-TOF instrument. The molecular weights were determined using a Waters GPC 2410 instrument, with THF as eluent, via a calibration curve of polystyrene as a standard. Thermogravimetric analysis (TGA) was conducted under a dry nitrogen gas flow at a heating rate of $20^{\circ} \mathrm{C} \mathrm{min}^{-1}$ on a Perkin-Elmer TGA 7 instrument. UV-vis absorption spectra were recorded on a HP-8453 UV-vis system. Cyclic 
voltammetry (CV) was carried out on a CHI-660A electrochemical work station in a three-electrode cell dipped in a $0.1 \mathrm{M}$ tetrabutylammonium hexafluorophosphate $\left(\mathrm{Bu}_{4} \mathrm{NPF}_{6}\right)$ acetonitrile solution under nitrogen protection at a scan rate of $100 \mathrm{mV} \mathrm{s}^{-1}$ and RT. In this three-electrode cell, a platinum rod, platinum wire, and saturated calomel electrode were used as a working electrode, counter electrode, and reference electrode, respectively. Polymers were coated on the surface of platinum rod electrode and all potentials were corrected against $\mathrm{Fc} / \mathrm{Fc}^{+}$. The morphology of the polymer/PCBM blend film was investigated by an AFM on a Veeco, DI Multimode NS-3D apparatus in a trapping mode under normal air condition at RT.

\subsection{Materials}

Monomers of tributyl(thiophen-2-yl)stannane (2), bis(4-bromophenyl)amine (5), and 2,6-bis(trimethyltin)-4,8-bis(2-ethylhexyloxy)benzo[1,2-b:4,5-b']dithiophene (M2) were obtained from commercial sources and used without further purification. Compound 4-bromo-7-(5-(2-ethylhexyl)thiophen-2-yl)benzo[c]$[1,2,5]$ thiadiazole $(\mathbf{1})^{[21]}$ was prepared according to the literature. The detailed synthetic processes of the other compounds are described as follows. Toluene and THF were distilled from sodium benzophenone under nitrogen before use. All the other reagents and solvents used in this work were commercially purchased and used without further purification. All the chromatographic separations were carried out on silica gel (200-300 mesh).

\subsubsection{Synthesis of 4-(5-(2-ethylhexyl)thiophen-2-yl)-7- (thiophen-2-yl)benzo[c][1,2,5]thiadiazole (3)}

A mixture of 4-bromo-7-(5-(2-ethylhexyl)thiophen-2-yl)benzo[c]$[1,2,5]$ thiadiazole $(1.92 \mathrm{~g}, 4.70 \mathrm{mmol}), 2$-tributyl(thiophen-2-yl) stannane $(2.10 \mathrm{~g}, 5.60 \mathrm{mmol})$, and $\mathrm{Pd}\left(\mathrm{PPh}_{3}\right)_{4}(0.16 \mathrm{~g})$ was dissolved in $30 \mathrm{~mL}$ of toluene. The mixture was degassed and vigorously stirred at $80{ }^{\circ} \mathrm{C}$ for $24 \mathrm{~h}$ under a nitrogen atmosphere. After cooling to room temperature (RT), $30 \mathrm{~mL}$ of water were added into the mixture. The resulting mixture was extracted with dichloromethane (DCM) $(30 \mathrm{~mL} \times 3)$. The combined organic layer was dried over anhydrous magnesium sulfate $\left(\mathrm{MgSO}_{4}\right)$ and distilled to remove the solvent. The residue was purified by silicagel column chromatography using petroleum ether (PE)/DCM $(\mathrm{V} / \mathrm{V}, 7 / 1)$ as the eluent to yield $1.70 \mathrm{~g}(87.1 \%)$ of 3 as a red solid. ${ }^{1} \mathrm{H}$ NMR (400 MHz, $\mathrm{CDCl}_{3}$, TMS, $\delta$ ): 8.10 (d, $J=2.92 \mathrm{~Hz}, 1 \mathrm{H}$ ), 7.94 (d, $J=3.19 \mathrm{~Hz}, 1 \mathrm{H}), 7.86$ (d, $J=7.50 \mathrm{~Hz}, 1 \mathrm{H}), 7.80(\mathrm{~d}, J=7.63 \mathrm{~Hz}$, $1 \mathrm{H}), 7.44(\mathrm{~d}, J=4.74 \mathrm{~Hz}, 1 \mathrm{H}), 7.20(\mathrm{~m}, 1 \mathrm{H}), 6.88(\mathrm{~d}, J=2.71 \mathrm{~Hz}, 1 \mathrm{H})$, $2.89-2.86(\mathrm{t}, J=5.71 \mathrm{~Hz}, 2 \mathrm{H}), 1.78-1.70(\mathrm{~m}, 2 \mathrm{H}), 1.42-1.28(\mathrm{~m}$, $10 \mathrm{H}), 0.89-0.86(t, J=6.03 \mathrm{~Hz}, 3 \mathrm{H})$.

4.2.2. Synthesis of 4-(5-iodothiophen-2-yl)-7-(5-(2ethylhexyl)thiophen-2-yl)benzo[c] [1,2,5]thiadiazole (4)

$\mathrm{N}$-iodosuccinimid ( $0.85 \mathrm{mg}, 3.8 \mathrm{mmol}$ ) was added to compound 3 $(1.57 \mathrm{~g}, 3.8 \mathrm{~mol})$ and $100 \mathrm{~mL}$ of $\mathrm{CHCl}_{3}$ at $0{ }^{\circ} \mathrm{C}$ in the dark. The mixture was stirred for $5 \mathrm{~h}$ at RT under an inert atmosphere, then washed with water. The resulting organic phase was dried over anhydrous $\mathrm{MgSO}_{4}$ and the solvent was distilled off. The residue was purified by silica gel column chromatography using PE/DCM $(V / V, 10 / 1)$ as eluent to yield $1.61 \mathrm{~g}(78.9 \%)$ of 4 as a red solid. ${ }^{1} \mathrm{H}$
NMR (400 MHz, CDCl, TMS, $\delta$ ): 7.95 (d, $J=3.38 \mathrm{~Hz}, 1 \mathrm{H}$ ), 7.78 (s, $2 \mathrm{H}), 7.69(\mathrm{~d}, J=3.64 \mathrm{~Hz}, 1 \mathrm{H}), 7.34(\mathrm{~d}, J=3.65 \mathrm{~Hz}, 1 \mathrm{H}), 6.88(\mathrm{~d}, J=$ $3.10 \mathrm{~Hz}, 1 \mathrm{H}), 2.90-2.86$ (t, $J=7.50 \mathrm{~Hz}, 2 \mathrm{H}), 1.78-1.71(\mathrm{~m}, 2 \mathrm{H}), 1.42-$ $1.28(\mathrm{~m}, 10 \mathrm{H}), 0.88-0.86(\mathrm{t}, J=6.63 \mathrm{~Hz}, 3 \mathrm{H})$.

\subsubsection{Synthesis of N,N-bis(4-bromophenyl)-5-(7-(5-(2-} ethylhexyl)thiophen-2-yl) benzo[c][1, 2,5]thiadiazol-4-yl) thiophen-2-amine (M1)

A mixture of compound 4 (100.0 mg, $0.186 \mathrm{mmol})$, bis(4-bromophenyl)amine (60.4 mg, $0.186 \mathrm{mmol}), \mathrm{CuI}(10.0 \mathrm{mg}, 0.049 \mathrm{mmol})$, $\mathrm{KOH}$ (10.0 mg, $0.178 \mathrm{mmol})$, and 1,10-phenanthroline (10.0 mg) in toluene $(20 \mathrm{~mL})$ was degassed for $30 \mathrm{~min}$ at $\mathrm{RT}$ and vigorously stirred at $120{ }^{\circ} \mathrm{C}$ for $0.5 \mathrm{~h}$ under a nitrogen atmosphere. After cooling to RT, the mixture was mixed with water $(50 \mathrm{~mL})$ and extracted with DCM $(30 \mathrm{~mL} \times 3)$. The organic layer was collected and dried over anhydrous $\mathrm{MgSO}_{4}$. Afterwards, the solvent was distilled off and the residue was purified by silica-gel column chromatography using PE/DCM $(V / V, 10 / 1)$ as eluent to yield $51 \mathrm{mg}$ (37.2\%) of $\mathbf{M} 1$ as a red solid. ${ }^{1} \mathrm{H}$ NMR $\left(400 \mathrm{MHz}, \mathrm{CDCl}_{3}\right.$, TMS,

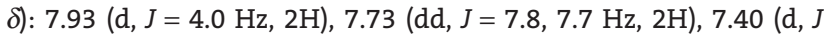
$=8.7 \mathrm{~Hz}, 4 \mathrm{H}), 7.09$ (d, $J=8.7 \mathrm{~Hz}, 4 \mathrm{H}), 6.87(\mathrm{~d}, J=3.5 \mathrm{~Hz}, 1 \mathrm{H}), 6.74$ (d, $J=4.0 \mathrm{~Hz}, 1 \mathrm{H}), 2.88$ (t, $J=7.6 \mathrm{~Hz}, 2 \mathrm{H}), 1.74(\mathrm{t}, J=7.3 \mathrm{~Hz}, 2 \mathrm{H})$, $1.35(\mathrm{~m}, 10 \mathrm{H}), 0.88(\mathrm{t}, J=7.0 \mathrm{~Hz}, 3 \mathrm{H}) \cdot{ }^{13} \mathrm{C} \mathrm{NMR}\left(100 \mathrm{MHz}, \mathrm{CDCl}_{3}\right.$, $\delta): 152.65,152.55,151.65,148.05,146.36,136.76,133.80,132.45$, $127.58,126.53,126.07,125.28,125.13,125.00,124.88,124.52$, $121.64,116.45,31.88,31.65,30.34,29.36,29.23,29.18,22.67$, 14.08. MALDI-TOF MS $(m / z)$ for $\mathrm{C}_{34} \mathrm{H}_{31} \mathrm{Br}_{2} \mathrm{~N}_{3} \mathrm{~S}_{3}$, calcd: 737.00; found: 737.02 .

\subsubsection{Synthesis of PDPAT-BDT-BT}

A mixture of $\mathbf{M} 1$ (110.0 mg, $0.149 \mathrm{mmol}$ ), M2 (115.3 mg, $0.149 \mathrm{mmol})$, and $\mathrm{P}(\mathrm{o}-\mathrm{Tol})_{3}(10.0 \mathrm{mg}), \mathrm{Pd}_{2}(\mathrm{dba})_{3}(5.0 \mathrm{mg})$ in toluene $(15 \mathrm{~mL})$ was degassed for $30 \mathrm{~min}$ under nitrogen atmosphere and heated to $90{ }^{\circ} \mathrm{C}$ under stirring vigorously for $24 \mathrm{~h}$. After cooling to $\mathrm{RT}$, the resulting mixture was poured onto acetone and the polymer precipitate was formed. The precipitate was collected and extracted with diethyl ether and $\mathrm{CHCl}_{3}$ successively in Soxhlet apparatus for $12 \mathrm{~h}$ for each process. The extracted $\mathrm{CHCl}_{3}$ solution was collected and concentrated to remove the great mass of $\mathrm{CHCl}_{3}$. The residual was dropped into acetone $(150 \mathrm{~mL})$ to yield polymer precipitate again. The precipitate was collected and dried under vacuum over night to give PDPAT-BDT-BT as a dark solid (110 mg, 72.4\%). ${ }^{1} \mathrm{H}$ NMR (400 MHz, $\left.\mathrm{CDCl}_{3}, \mathrm{TMS}, \delta\right): 7.96$ (d, $J=$ $28.2 \mathrm{~Hz}, 2 \mathrm{H}), 7.70(\mathrm{br}, 6 \mathrm{H}), 7.61(\mathrm{~d}, J=23.8 \mathrm{~Hz}, 2 \mathrm{H}), 7.35(\mathrm{br}, 4 \mathrm{H})$, 6.87 (br, 2H), 4.23-4.21(m, 4H), 2.90-2.86 (t, $J=7.35 \mathrm{~Hz}, 2 \mathrm{H}), 1.84-$ $1.27(\mathrm{br}, 30 \mathrm{H}), 1.04-0.87$ (br, $15 \mathrm{H})$. Anal. Calcd. for $\left(\mathrm{C}_{60} \mathrm{H}_{69} \mathrm{~N}_{3} \mathrm{O}_{2} \mathrm{~S}_{5}\right)$ : C 70.34, H 6.79, N 4.10; Found: C 69.97, H 6.76, N 3.96.

\section{Supporting Information}

Supporting Information is available from the Wiley Online Library or from the author.

Acknowledgements: The authors acknowledge financial support from the Major Program for Cultivation of the National Natural Science Foundation of China (91233112), the National Natural

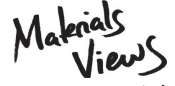

www.MaterialsViews.com
Macromol. Chem. Phys. 2014, 215, 2075-2083

(c) 2014 WILEY-VCH Verlag GmbH \& Co. KGaA, Weinheim 
Science Foundation of China (21172187, 51273168, 21202139), the Innovation Group and Xiangtan Joint Project of Hunan Natural Science Foundation (12JJ7002 and 12JJ8001), the Open Project for National Key Laboratory of Luminescent Materials and Devices (2014-skllmd-10), the Key Project of Hunan Province Education Department (13A102), and the Hunan Postgraduate Science Foundation for Innovation (CX2013B268).

Received: June 4, 2014; Revised: July 19, 2014; Published online: August 25, 2014; DOI: 10.1002/macp.201400298

Keywords: benzo[1,2-b:4,5-b']dithiophene; benzothiadiazole; photovoltaic properties; polymer solar cells; side-chain polymers

[1] a) T.-Y. Chu, J. P. Lu, S. Beaupré, Y. G. Zhang, J.-R. Pouliot, J. Y. Zhou, A. Najari, M. Leclerc, Y. Tao, Adv. Funct. Mater. 2012, 22, 2345; b) N. Wang, Z. Chen, W. Wei, Z. H. Jiang, J. Am. Chem. Soc. 2013, 135, 17060; c) W.-H. Chang, J. Gao, L. T. Dou, C.-C. Chen, Y . S. Liu, Y. Yang, Adv. Energy Mater. 2013, 4, 864; d) P. Bujak, I. Kulszewicz-Bajer, M. Zagorska, V. Maurel, I. Wielgus, A. Pron, Chem. Soc. Rev. 2013, 42, 8895; e) K.-J. Baeg, M. Caironi, Y.-Y. Noh, Adv. Mater. 2013, 25, 4210.

[2] a) J. B. You, L. T. Dou, K. Yoshimura, T. Kato, K. Ohya, T. Moriarty, K. Emery, C.-C. Chen, J. Gao, G. Li, Y. Yang, Nat. Commun. 2013, 4, 1446; b) J. B. You, C.-C. Chen, Z. R. Hong, K. Yoshimura, K. Ohya, R. Xu, S. L. Ye, J. Gao, G. Li, Y. Yang, Adv. Mater. 2013, 25, 3973; c) Y. S. Liu, C.-C. Chen, Z. R. Hong, J. Gao, M. Yang, H. P. Zhou, L. T. Dou, G. Li, Y. Yang, Sci. Rep. 2013, 28, 3356.

[3] a) D. F. Dang, W. C. Chen, R. O. Yang, W. G. Zhu, W. Mammod, E. Wang, Chem. Commun. 2013, 49, 9335; b) H.-C. Chen, Y.-H. Chen, C.-C. Liu, Y.-C. Chien, S.-W. Chou, P.-T. Chou, Chem. Mater. 2012, 24, 4766; c) Y. Wang, Y. Liu, S. J. Chen, R. X. Peng, Z. Y. Ge, Chem. Mater. 2013, 25, 3196; d) S. Li, A. Y. Li, J. Yu, A. S. Zhong, S. A. Chen, R. L. Tang, X. Y. Deng, J. G. Oin, O. O. Li, Z. Li, Macromol. Rapid Commun. 2013, 34, 227.

[4] a) D. H. Kim, H. J. Song, S. W. Heo, K. W. Song, D. K. Moon, Sol. Energy Mater. Sol. Cells 2014, 120, 94; b) H.-C. Chen, Y.-H. Chen, C.-H. Liu, Y.-H. Hsu, Y.-C. Chien, W.-T. Chuang, C.-Y. Cheng, C.-L. Liu, S.-W. Chou, S.-H. Tung, P.-T. Chou, Polym. Chem. 2013, 4, 3411; c) J.-H. Kim, C. E. Song, H. U. Kim, A. C. Grimsdale, S.-J. Moon, W. S. Shin, S. K. Choi, D.-H. Hwang, Chem. Mater. 2013, 25, 2722.

[5] a) Y.-C. Chen, C.-Y. Hsu, C.-Y. Ho, Y.-T. Tao, J. T. Lin, Organic Electronics 2013, 14, 2290; b) T. Jia, O. Hou, K. Xiong, O. Li, L. T. Hou, J. Mater. Sci: Mater. Electron. 2014, 25, 1639; c) K. Zhang, Y. T. Tao, C. L. Yang, H. You, Y. Zou, J. G. Oin, D. G. Ma, Chem. Mater. 2008, 20, 7324.

[6] a) H. Tan, X. P. Deng, J. T. Yu, B. F. Zhao, Y. F. Wang, Y. Liu, W. G. Zhu, H. B. Wu, Y. Cao, Macromolecules 2013, 46, 113; b) H. Tan, J. T. Yu, Y. F. Wang, J. H. Chen, O. Tao, Y. Liu, J. Huang, W. G. Zhu, Org. Electron. 2013, 14, 1510; c) K. X. Nie, H. Tan, X. P. Deng, Y. F. Wang, O. Chen, Y. Huang, Y. Liu, C. C. Yang, Z. R. Huang, M. X. Zhu, W. G. Zhu, J. Polym. Sci., A. Polym. Chem. 2013, 51, 4103.

[7] a) H. Y. Song, H. Tong, Z. Y. Xie, L. X. Wang, F. S. Wang, Polymer 2012, 53, 5103; b) J. T. Bloking, X. Han, A. T. Higgs, J. P. Kastrop, L. Pandey, J. E. Norton, C. Risko, C. E. Chen, J.-L. Brédas, M. D. McGehee, A. Sellinger, Chem. Mater. 2011, 23, 5484; c) D. G. Patel, F. Feng, Y.-Y. Ohnishi, K. A. Abboud,
S. Hirata, K. S. Schanze, J. R. Reynolds, J. Am. Chem. Soc. 2012, 134, 2599; d) R. S. Kularatne, P. Sista, H. O. Nguyen, M. P. Bhatt, M. C. Biewer, M. C. Stefan, Macromolecules 2012, 45, 7855; e) E. Wang, M. Wang, L. Wang, C. H. Duan, J. Zhang, W. Z. Cai, C. He, H. B. Wu, Y. Cao, Macromolecules 2009, 42, 4410.

[8] a) S. Ellinger, K. R. Graham, P. J. Shi, R. T. Farley, T. T. Steckler, R. N. Brookins, P. Taranekar, J. G. Mei, L. A. Padilha, T. R. Ensley, H. H. Hu, S. Webster, D. J. Hagan, E. W. V. Stryland, K. S. Schanze, J. R. Reynolds, Chem. Mater. 2011, 23, 3805; b) X. F. Liu, Y. M. Sun, L. A. Perez, W. Wen, M. F. Toney, A. J. Heeger, G. C. Bazan, J. Am. Chem. Soc. 2012, 134, 20609; c) K. M. Omer, S.-Y. Ku, J.-Z. Cheng, S.-H. Chou, K.-T. Wong, A. J. Bard, J. Am. Chem. Soc. 2011, 133, 5492; d) Y. L. Ma, O. D. Zheng, Z. G. Yin, D. D. Cai, S.-C. Chen, C. O. Tang, Macromolecules 2013, 46, 4813.

[9] a) J. Warnan, A. E. Labban, C. Cabanetos, E. T. Hoke, P. K. Shukla, C. Risko, J.-L. Bredas, M. D. McGehee, P. M. Beaujuge, Chem. Mater. 2014, 26, 2299; b) J.-H. Kim, C. E. Song, B. Kim, I.-N. Kang, W. S. Shin, D.-H. Hwang, Chem. Mater. 2014, 26, 1234; c) Y. Wang, F. Yang, Y. Liu, R. X. Peng, S. J. Chen, Z. Y. Ge, Macromolecules 2013, 46, 1368; d) Y. Wang, Y. Liu, S. J. Chen, R. X. Peng, Z. Y. Ge, Chem. Mater. 2013, 25, 3196; e) P. Shen, H. J. Bin, L. Xiao, Y. F. Li, Macromolecules 2013, 46, 9575; f) J.-H. Kim, S. A. Shin, J. B. Park, C. E. Song, W. S. Shin, H. Yang, Y. F. Li, D.-H. Hwang, Macromolecules 2014, 47, 1613; g) M. J. Zhang, Y. Gu, X. Guo, F. Liu, S. Q. Zhang, L. J. Hu, T. P. Russell, J. H. Hou, Adv. Mater. 2013, 25, 4944.

[10] a) Y. Z. Lin, P. Cheng, Y. Liu, X. G. Zhao, D. S. Li, J. H. Tan, W. P. Hu, Y. F. Li, X. W. Zhan, Sol. Energy Mater. Sol. Cells 2012, 99, 301; b) Y. M. Zhang, H. Tan, M. J. Xiao, X. C. Bao, O. Tao, Y. F. Wang, Y. Liu, R. O. Yang, W. G. Zhu, Org. Electron. 2014, 15, 1173; c) O. O. Shi, P. Cheng, Y. F. Li, X. W. Zhan, Adv. Energy Mater. 2012, 2, 63; d) Y.-H. Chen, L.-Y. Lin, C.-W. Lu, F. Lin, Z.-Y. Huang, H.-W. Lin, P.-H. Wang, Y.-H. Liu, K.-T. Wong, J. G. Wen, D. J. Miller, S. B. Darling, J. Am. Chem. Soc. 2012, 134, 13616; e) J. X. Zhang, W. Chen, J. Rojas, E. V. Jucov, T. V. Timofeeva, T. C. Parker, S. Barlow, S. R. Marder, J. Am. Chem. Soc. 2013, 135, 16376; f) L. Y. Bian, D. Yang, L. M. Yin, J. Zhang, W. H. Tang, Macromol. Chem. Phys. 2013, 214, 2136.

[11] H. Tan, X. P. Deng, J. T. Yu, J. H. Chen, K. X. Nie, Y. Huang, Y. Liu, Y. F. Wang, M. X. Zhu, W. G. Zhu, J. Polym. Sci., Part A: Polym. Chem. 2013, 51, 1051

[12] W. W. Li, W. S. Roelofs, M. Turbiez, M. M. Wienk, R. A. J. Janssen, Adv. Mater. 2014, 26, 3304.

[13] W. W. Li, K. H. Hendriks, A. Furlan, W. S. C. Roelofs, S. C. J. Meskers, M. M. Wienk, R. A. J. Janssen, Adv. Mater. 2014, 26, 1565.

[14] a) J.-M. Jiang, H.-K. Lin, Y.-C. Lin, H.-C. Chen, S.-C. Lan, C.-K. Chang, K.-H. Wei, Macromolecules. 2014, 47, 70; b) O. O. Shi, P. Cheng, Y. F. Li, X. W. Zhan, Adv. Energy Mater. 2012, 2, 63 .

[15] a) H. Yi, S. A. Faifi, A. Iraqi, D. C. Watters, J. Kingsley, D. G. Lidzey, J. Mater. Chem. 2011, 21, 13649; b) Y. Huang, M. O. Zhang, L. Ye, X. Guo, C. C. Han, Y. F. Li, J. H. Hou, J. Mater. Chem. 2012, 22, 5700; c) R. M. Duan, L. Ye, X. Guo, Y. Huang, P. Wang, S. O. Zhang, J. P. Zhang, L. J. Huo, J. H. Hou, Macromolecules 2012, 45, 3032; d) H. J. Song, D. H. Kim, E. J. Lee, J. R. Haw, D. K. Moon, Sol. Energy Mater. Sol. Cells 2014, 123, 112.

[16] Y. F. Li, Y. Cao, J. Gao, D. L. Wang, G. Yu, A. J. Heeger, Synth. Met. 1999, 99, 243. 
[17] Y. X. Xu, C.-C. Chueh, H.-L. Yip, F. Z. Ding, Y. X. Li, C. Z. Li, X. S. Li, W. C. Chen, A. K.-Y. Jen, Adv. Mater. 2012, 24, 6356.

[18] L. Pandey, C. Risko, J. E. Norton, J.-L. Brédas. Macromolecules 2012, 45, 6405.

[19] J. Zhang, W. Z. Cai, F. Huang, E. Wang, C. M. Zhong, S. J. Liu, M. Wang, C. H. Duan, T. B. Yang, Y. Cao, Macromolecules 2011, 44, 894 .
[20] a) J. Coughlin, Z. Henson, G. C. Welch, G. C. Bazan, Accounts 2014, 47, 257; b) K. Li, Z. J. Li, K. Feng, X. P. Xu, L. Y. Wang, O. Peng, J. Am. Chem. Soc. 2013, 135, 13549; c) J.-H. Kim, S. A. Shin, J. B. Park, C. E. Song, W. S. Shin, H. C. Yang, Y. F. Li, D.-H. Hwang, Macromolecules 2014, 47, 1613.

[21] J. Zhang, Y. Yang, C. He, Y. J. He, G. J. Zhao, Y. F. Li, Macromolecules 2009, 42, 7619. 